BULLETIN Bulletin hispanique

HISPANIQUE Université Michel de Montaigne Bordeaux

110-1 | 2008

Varia

\title{
David Mañero Lozano (ed.), Segunda parte de la vida del pícaro Guzmán de Alfarache
}

David Álvarez

\section{(2) OpenEdition}

1 Journals

Édition électronique

URL : https://journals.openedition.org/bulletinhispanique/712

DOI : 10.4000/bulletinhispanique. 712

ISSN : 1775-3821

Éditeur

Presses universitaires de Bordeaux

Édition imprimée

Date de publication : 1 juin 2008

Pagination : 396

ISBN : 978-2-86781-511-9

ISSN : 0007-4640

Référence électronique

David Álvarez, «David Mañero Lozano (ed.), Segunda parte de la vida del pícaro Guzmán de Alfarache », Bulletin hispanique [En ligne], 110-1 | 2008, mis en ligne le 10 février 2014, consulté le 18 septembre 2021. URL : http://journals.openedition.org/bulletinhispanique/712 ; DOI : https://doi.org/10.4000/ bulletinhispanique.712

Tous droits réservés 
Segunda parte de la vida del pícaro Guzmán de Alfarache. David MaÑero Lozano (ed.). - Madrid, Cátedra, 2007, 625 p. : índice de voces (colleción Letras Hispánicas) - ISBN : 978-84-376-2403-7

Parue en 1602 à Valence, la Segunda parte de la vida del picaro Guzmán de Alfarache, signée du pseudonyme de Mateo Luján de Sayavedra, connut en son temps un immense succès éditorial, jusqu'à la publication de la Seconde Partie authentique du Guzmán par Mateo Alemán. Bien qu'elle soit tombée de nos jours dans un oubli presque total, l'œuvre de Luján fut en effet éditée dix fois entre 1602 et 1604 . L'édition critique de David Mañero Lozano vient donc combler une lacune en offrant au public un texte méconnu qui, outre son intérêt intrinsèque, apporte un éclairage nouveau sur le Guzmán de Alfarache et, plus largement, sur l'évolution du genre picaresque.

Dans son introduction, David Mañero Lozano aborde successivement tous les grands axes de recherche ayant retenu l'attention de la critique depuis le début du siècle dernier. Il propose une indispensable mise au point sur l'énigme littéraire que constitue l'identité du continuateur, avant de s'intéresser aux accusations de plagiat dont ce dernier a fait l'objet. Il examine ensuite la lecture que fait Luján de la Première Partie du Guzmán authentique, puis la stratégie mise en place par Alemán pour discréditer son continuateur dans sa propre Seconde Partie. David Mañero Lozano offre enfin une analyse détaillée de la trajectoire éditoriale de l'œuvre, qui n'avait jamais fait jusqu'ici l'objet d'un travail approfondi. Il propose de ce fait pour la première fois un texte fiable, établi à partir d'un examen rigoureux des différentes éditions répertoriées à ce jour. L'appareil de notes, lui aussi très soigné, apporte de nombreux éclaircissements et commentaires historicophilologiques indispensables à l'intelligence du texte. Il permet en outre de distinguer ce qui, dans l'œuvre, relève de l'emprunt direct à d'autres sources, et ce que l'on doit à l'imagination du continuateur.

L'ensemble de ce travail conduit finalement à s'interroger sur la valeur esthétique du Guzmán apocryphe et permet de mieux cerner un projet d'écriture souvent dénié à l'auteur valencien, dont l'œuvre a longtemps été perçue comme une version dégradée du roman de Mateo Alemán. Lédition de David Mañero Lozano, sans nul doute appelée à devenir le texte de référence sur la continuation de Luján, fournit donc un précieux instrument de travail et ouvre de nouvelles perspectives de recherche.

David ÁLVAREZ 